\title{
Validation of a Florida Strawberry Anthracnose Fruit Rot (AFR) Warning System in lowa
}

Xiaoyu Zhang and Jean C. Batzer, Department of Plant Pathology and Microbiology, Iowa State University, Ames; Xun Li, College of Plant Protection, Hunan Agricultural University, Changsha, China; Natalia A. Peres, Department of Plant Pathology, Gulf Coast Research and Education Center, University of Florida, Wimauma, FL; and Mark L. Gleason, ${ }^{\dagger}$ Department of Plant Pathology and Microbiology, Iowa State University, Ames

\begin{abstract}
Field validation of a disease-warning system for strawberry anthracnose fruit rot (AFR), caused by Colletotrichum acutatum sensu lato, that was originally developed for use in Florida was conducted in Iowa from 2012 to 2014. Day-neutral strawberry (cv. Tristar) was artificially inoculated with the pathogen at the start of the fruit maturation period. A factorial combination in replicated trials of two spray timing methods (the Florida warning system and prescheduled, calendar-based timing) and two fungicides (captan and pyraclostrobin) was compared, along with a nonsprayed control. The calendar-based and warning system-based treatments provided statistically equivalent control of AFR incidence

compared with the nonsprayed control, and the warning system treatments required an average of 1.7 fewer fungicide sprays annually than the calendar-based treatments. Further analysis of the field data suggested that the warning system might underestimate AFR risk under high disease pressure; in these circumstances, a lower action threshold value may need to be adopted. Overall, these results indicated that the Florida warning system can be valuable for helping Midwest strawberry growers control AFR with less reliance on fungicide sprays, but it may require modification to account for periods of high inoculum pressure, subject to results of further field trials.
\end{abstract}

Strawberry anthracnose is a fungal disease complex caused by Colletotrichum acutatum sensu lato (hereafter referred to as $C$. $a c u$ tatum), C. gloeosporioides, and $C$. fragariae. The primary pathogen of anthracnose fruit rot (AFR) is C. acutatum (Smith 1990). Epidemics can lead to substantial yield losses even in well-managed fields (Howard et al. 1992). AFR has long been a concern in the southern United States, and more recently it has become a threat to Midwest U.S. strawberry growers (Ellis and Madden 1993; Poling 2008). Quiescent infections on asymptomatic nursery plants can be transported long distances to production fields on transplants (Leandro et al. 2001, 2003b). Dissemination of secondary conidia on foliage, still in the absence of symptoms, can set the stage for unexpected epidemics (Leandro et al. 2001). In the Midwest, sunken brown AFR lesions appear on fruit as strawberries begin to ripen (Ellis and Madden 1993; Leandro et al. 2001, 2003b).

Commercial management of strawberry AFR relies on protective fungicides applied on a calendar-timed basis, but effectiveness of this strategy is erratic (Peres et al. 2010; Turechek et al. 2006). Reliable alternatives have been sought to reduce reliance on fungicide sprays and lessen the risk of resistance development. Temperature and leaf wetness duration (LWD) were found to be critical factors for $C$. $a c u$ tatum infection in laboratory experiments; 4 to $6 \mathrm{~h}$ of LWD within the optimum temperature range $\left(25\right.$ to $\left.30^{\circ} \mathrm{C}\right)$ was necessary to cause significant fruit damage (Wilson et al. 1990). Based on this model, the Strawberry Advisory System (StAS) was developed and field validated for Florida growers (MacKenzie and Peres 2012; Pavan et al. 2011). The StAS saves approximately $50 \%$ of fungicide sprays without compromising AFR control and has been widely adopted by Florida and South Carolina growers (Cordova et al. 2017).

Climate, production systems, and strawberry cultivars in Iowa differ markedly from those in Florida and South Carolina. Commercial strawberries in subtropical Florida, produced in annual plasticulture

${ }^{\dagger}$ Corresponding author: M. L. Gleason; E-mail: mgleason@iastate.edu

Funding: Funding was provided by National Institute of Food and Agriculture (grant no. 2010-51181-21113).

Accepted for publication 19 June 2018.

() 2019 The American Phytopathological Society systems, are transplanted during September and October and harvested from November to late March. Weather conditions during this period are often favorable for development of AFR epidemics (MacKenzie and Peres 2012). In contrast, strawberry production systems in the continental climate of Iowa are varied; June-bearing cultivars in perennial matted-row culture remain predominant, but an increasing number of growers are using annual or perennial dayneutral cultivars in plasticulture systems. The vulnerability of dayneutral cultivars to midsummer AFR epidemics is a major limiting factor to expansion of this potentially profitable production system in the Upper Midwest (Rowley et al. 2011; Sjulin 2008). A first step toward adapting the StAS to Iowa is to validate its performance under Iowa conditions. The objective of this study was to assess the efficacy of the Florida-based AFR-StAS on day-neutral strawberries in Iowa.

\section{Materials and Methods}

StAS algorithm. The AFR-StAS model predicts the level of AFR incidence under a scenario in which no fungicides are applied. The equation underlying this system predicts the level of AFR risk (INF) from wetness duration $(W)$ and temperature $(T)$ as follows:

$$
\begin{aligned}
\ln [\mathrm{INF} /(1-\mathrm{INF})] & =-3.70+0.33 W-0.069 W T \\
& +0.0050 W T^{2}-0.93 \times 10^{-4} W T^{3}
\end{aligned}
$$

In the equation, INF is disease incidence, $W$ is the daily duration of wetness periods, and $T$ is average temperature $\left({ }^{\circ} \mathrm{C}\right)$ during the wet periods (Wilson et al. 1990). The equation predicted infection of the pathogen and indicated expected incidence of AFR if no fungicides were applied. In Florida, moderate AFR risk was assumed to occur when INF was $>0.15$ (i.e., predicted incidence in the absence of fungicide sprays exceeded $15 \%$ ) and high risk when INF was $>0.5$ (predicted incidence of $>50 \%$ in the absence of fungicide sprays) (MacKenzie and Peres 2012). During implementation and field validation in Florida, fungicide spray timing and fungicide product selection were selected according to the risk level determined by the model; the AFR-StAS prescribes use of captan fungicide when the risk of AFR is moderate and the quinone-outside inhibitor (QoI) fungicide pyraclostrobin when the risk of AFR is high (MacKenzie and Peres 2012).

Planting site, materials, and maintenance. Annual plantings of the day-neutral strawberry cultivar Tristar were established in mid- to 
late May at the Iowa State University Horticulture Research Station near Gilbert, Iowa, in 2012, 2013, and 2014. Transplants were established in 27.4-m-long raised beds on white-on-black plastic mulch with $1.8-\mathrm{m}$ row centers and drip irrigation in staggered double rows with $0.3-\mathrm{m}$ spacing between plants. Within each mulched strip, 3.0-m-long subplots were alternated with nonplanted, 3-m-long strips to minimize interplot interference. Each subplot replicate contained 20 plants. The experiment was conducted in a randomized complete block design with five treatments and four replications per treatment. Treatment rows were alternated with nonsprayed guard rows (cv. Tristar). For weed control, a 0.15-m-deep layer of chopped cornstalk mulch was placed between the raised beds after planting. Before plastic mulch placement, $12.33 \mathrm{~kg} / \mathrm{ha}$ of urea was broadcast incorporated; when the plants began bearing fruit, the plot was fertigated weekly with 20-10-20 Peat-Lite plus urea (0.34 and $1.19 \mathrm{~kg} / \mathrm{ha}$, respectively) (Petersen Products Co., Fredonia, WI). Flowers and runners were removed twice weekly until mid-July. After fruiting onset, tarnished plant bug (Lygus lineolaris) was controlled with two sprays of Danitol 2.4 EC (0.22 kg of active ingredient [a.i.]/ha) and one spray of Assail 70 WP (200 liters/ha) per year; insecticides were applied when incidence of tarnished plant bug damage on harvested fruit was $>5 \%$. In 2012, fungicide applications started from 1 July, prior to inoculation, to reduce the risk of epidemics caused by $C$. acutatum originating from the nursery transplants. In 2013 and 2014, no fungicide sprays were applied before the inoculation date, because this was judged to be unnecessary owing to absence of disease pressure associated with transplants.

Inoculum preparation and inoculation. A mixture of equal proportions of $C$. acutatum strains 03.32, 05.226, and 11.101 from Florida, and NC-2 from North Carolina, was used for inoculations. Suspensions of C. acutatum conidia were prepared from 10-dayold cultures on potato dextrose agar that had been incubated at $26^{\circ} \mathrm{C}$ in darkness. Plates were flooded with sterile distilled water, and colonies were scraped with sterile swabs to dislodge conidia. Suspensions were filtered through three layers of cheesecloth and, with the aid of a hemacytometer, adjusted to final concentrations of $1.5 \times 10^{4}$ or $1.5 \times 10^{6}$ per milliliter. The lower concentration was used when weather conditions at the time of inoculation were highly favorable to inoculum survival and dissemination (warm and wet), whereas the higher concentration was used under less favorable weather conditions (cool or dry). Inoculations were performed at dusk in late July; during each inoculation, a total of 15 liters of the C. acutatum suspension was sprayed to runoff on all plants in the plot using a hand-pressurized backpack sprayer (model 452, Solo, Newport News, VA). Overhead irrigation was applied for $30 \mathrm{~min}$ before and after inoculation to promote pathogen colonization and infection when no rainfall occurred immediately before or after the inoculation.

Treatments and data collection. Four treatments were evaluated based on a factorial combination of two spray-timing methods (AFR-
StAS and calendar-based [every 10 days]) and two fungicides (captan and pyraclostrobin [Cabrio]), as well as a nonsprayed control. Captan 80WDG was applied at $1.65 \mathrm{~kg}$ of a.i./ha $(3.75 \mathrm{lb} / \mathrm{acre})$, and Cabrio 20EG was applied at $0.196 \mathrm{~kg}$ of a.i./ha (14 oz/acre). Treatments 1 and 2 were calendar-based sprays, beginning when removal of flowers was stopped. Treatments 3 and 4 were StAS-based sprays, for which two spray thresholds were set: a moderate-risk threshold (INF > 0.15) for captan and a high-risk threshold (INF > 0.5 ) for Cabrio. In this research, one application of all fungicide treatments was made 1 week after inoculation to set an equal start line for both timing methods. Treatment 5 was a nonsprayed control. A decision rule for using the warning system was that no fungicide sprays were made within a 7-day period after a previous application was made (Pavan et al. 2011).

Weather data recorded on the site were used to calculate INF from the time of inoculation until the end of harvest in each year. LWD was measured to estimate the wetness duration $(W)$ in the StAS algorithm using two printed-circuit sensors (model 237; Campbell Scientific, Logan, UT) that had been coated with off-white latex paint; these sensors were mounted on the end of a section of polyvinyl chloride (PVC) pipe at an angle of $45^{\circ}$ to horizontal and facing north. Two temperature sensors (model 107, Campbell Scientific) were shielded from direct sunlight by placing them inside the PVC pipes. All sensors were placed in the middle of the field about $0.6 \mathrm{~m}$ above the ground. Hourly average LWD and temperature were recorded by a data logger (model CR10, Campbell Scientific) that was downloaded twice weekly.

Mature berries were harvested two to three times weekly from late July to September. Weight and number of marketable fruit, fruit displaying AFR symptoms, and culls (damaged by non-AFR causes such as other rots, sunburn, animals, or insects) were recorded.

Data analysis. Yearly means of weight of marketable and cull fruit for each treatment were compared using the MIXED procedure of SAS (SAS Institute, Cary, NC), where treatment was considered as a fixed effect and block as a random effect. Fruit weight at each harvest was assumed to be independent from the previous harvests. Significant differences of the estimated least-squares means were determined based on least significant difference $(P=0.05)$.

To compare the StAS model prediction risk index INF with the AFR epidemic in the field, we simulated operation of the StAS model using a time series of count data including (i) number of diseased fruit (AFR_Cnt), (ii) disease incidence (AFR_Inc), and (iii) INF. Data from each harvest were treated as discrete rather than continuous data, because the interval between harvests varied from 2 to 4 days. We used the number of symptomatic fruit for each treatment at each harvest to model Poisson regression (Cameron and Pravin 2013). The AFR_Cnt data were overdispersed (i.e., the data had greater variance than their mean). As a result, the data were modeled using negative binomial regression, in which overdispersed data were treated as a mixture of data from different Poisson distributions.

Table 1. Year, treatment (Trt) number, fungicides, spray timing, number of sprays per season (NSS), anthracnose fruit rot incidence (AFRI), and yields per 20plant plot

\begin{tabular}{|c|c|c|c|c|c|c|c|c|c|c|c|c|c|c|c|c|c|}
\hline \multirow[b]{3}{*}{ Trt } & \multirow[b]{3}{*}{ Fungicide } & \multirow[b]{3}{*}{ Timing } & \multicolumn{5}{|c|}{$2012^{t}$} & \multicolumn{5}{|c|}{$2013^{u}$} & \multicolumn{5}{|c|}{$2014^{u}$} \\
\hline & & & \multirow[b]{2}{*}{ NSS } & \multirow{2}{*}{$\begin{array}{c}\text { AFRI } \\
(\%)\end{array}$} & \multicolumn{3}{|c|}{ Yield $^{\mathbf{v}}(\mathrm{g})$} & \multirow[b]{2}{*}{ NSS } & \multirow{2}{*}{$\begin{array}{c}\text { AFRI } \\
(\%)\end{array}$} & \multicolumn{3}{|c|}{ Yield (g) } & \multirow[b]{2}{*}{ NSS } & \multirow{2}{*}{$\begin{array}{c}\text { AFRI } \\
(\%)\end{array}$} & \multicolumn{3}{|c|}{ Yield (g) } \\
\hline & & & & & Mkt $^{\mathbf{w}}$ & AFR & Cull $^{\mathbf{x}}$ & & & Mkt & AFR & Cull & & & Mkt & AFR & Cull \\
\hline 1 & Captan & Calendar & 7 & 2.8 & $223.8 \mathrm{a}^{\mathrm{y}}$ & $5.8 \mathrm{a}$ & $22.1 \mathrm{a}$ & 4 & 1.7 & $255.6 \mathrm{a}$ & $4.2 \mathrm{a}$ & $42.2 \mathrm{a}$ & 6 & 13.6 & $170.1 \mathrm{a}$ & $26.0 \mathrm{a}$ & $15.3 \mathrm{a}$ \\
\hline 2 & Captan/Cabrio & Calendar & 7 & 3.1 & $216.1 \mathrm{a}$ & $6.4 \mathrm{a}$ & $18.5 \mathrm{a}$ & 4 & 1.4 & $245.6 \mathrm{a}$ & $2.6 \mathrm{a}$ & $40.0 \mathrm{a}$ & 6 & 8.2 & $191.7 \mathrm{a}$ & $12.1 \mathrm{a}$ & $15.7 \mathrm{a}$ \\
\hline 3 & Captan & $\mathrm{StAS}^{\mathrm{z}}$ & 5 & 6.6 & $217.5 \mathrm{a}$ & $16.8 \mathrm{~b}$ & $25.1 \mathrm{a}$ & 3 & 2.5 & $242.7 \mathrm{a}$ & $5.5 \mathrm{ab}$ & $41.1 \mathrm{a}$ & 5 & 13.6 & $157.6 \mathrm{a}$ & $25.5 \mathrm{a}$ & $15.7 \mathrm{a}$ \\
\hline 4 & Captan/Cabrio & StAS & 5 & 2.2 & $176.8 \mathrm{ab}$ & $4.0 \mathrm{a}$ & $22.3 \mathrm{a}$ & 3 & 2.1 & $247.7 \mathrm{a}$ & $4.8 \mathrm{ab}$ & $39.8 \mathrm{a}$ & 5 & 8.3 & $170.2 \mathrm{a}$ & $10.2 \mathrm{a}$ & $12.9 \mathrm{a}$ \\
\hline 5 & None & $\ldots$ & 0 & 19.1 & $149.6 \mathrm{~b}$ & $30.4 \mathrm{c}$ & $20.7 \mathrm{a}$ & 0 & 3.6 & $260.7 \mathrm{a}$ & $8.9 \mathrm{~b}$ & $37.7 \mathrm{a}$ & 0 & 57.3 & $44.7 \mathrm{~b}$ & $91.5 \mathrm{~b}$ & $13.4 \mathrm{a}$ \\
\hline
\end{tabular}

${ }^{\mathrm{t}}$ In 2012 fungicide applications started from 1 July before inoculation prevent the pathogen from originating from the nursery plants; the calendar-based fungicide spray was applied on 2 and 12 July, and the warning system treatments were sprayed on 6 July before inoculation at 18 July.

u In 2013 and 2014, fungicide applications began after inoculation: the warning system was initiated when the first warning was received after inoculation, and the calendar spray was started at the same time.

$\checkmark$ Yield per 20-plant subplot.

${ }^{w}$ Marketable (Mkt) yield is the average yield of marketable fruit per 20-plant subplot.

${ }^{x}$ Cull yield is the average weight including fruit damaged by other rots and insect pests per 20-plant subplot.

y Means followed by the same letter are not significantly different within each column according to Fisher's protected LSD at $P \leq 0.05$.

z StAS = Strawberry Advisory System. 
Two stochastic processes determining the value of AFR_Cnt were reflected in the data as follows: (i) yes/no situations (whether or not there would be at least one diseased fruit) were used when the data had many zeros (i.e., disease occurrence was low), or (ii) the number of diseased fruit was used during more severe AFR epidemics. To capture the characteristics of both stochastic processes in these disease data and model them together, we used a zero-inflated Poisson (ZIP) model (Lambert 1992) as follows:

$$
\operatorname{Pr}\left(y_{i}=j\right)=\left\{\begin{array}{cc}
\sigma+(1-\sigma) e^{-\lambda}, & j=0 \\
(1-\sigma) \frac{\lambda^{j} e^{-\lambda}}{j !}, & j>0
\end{array}\right.
$$
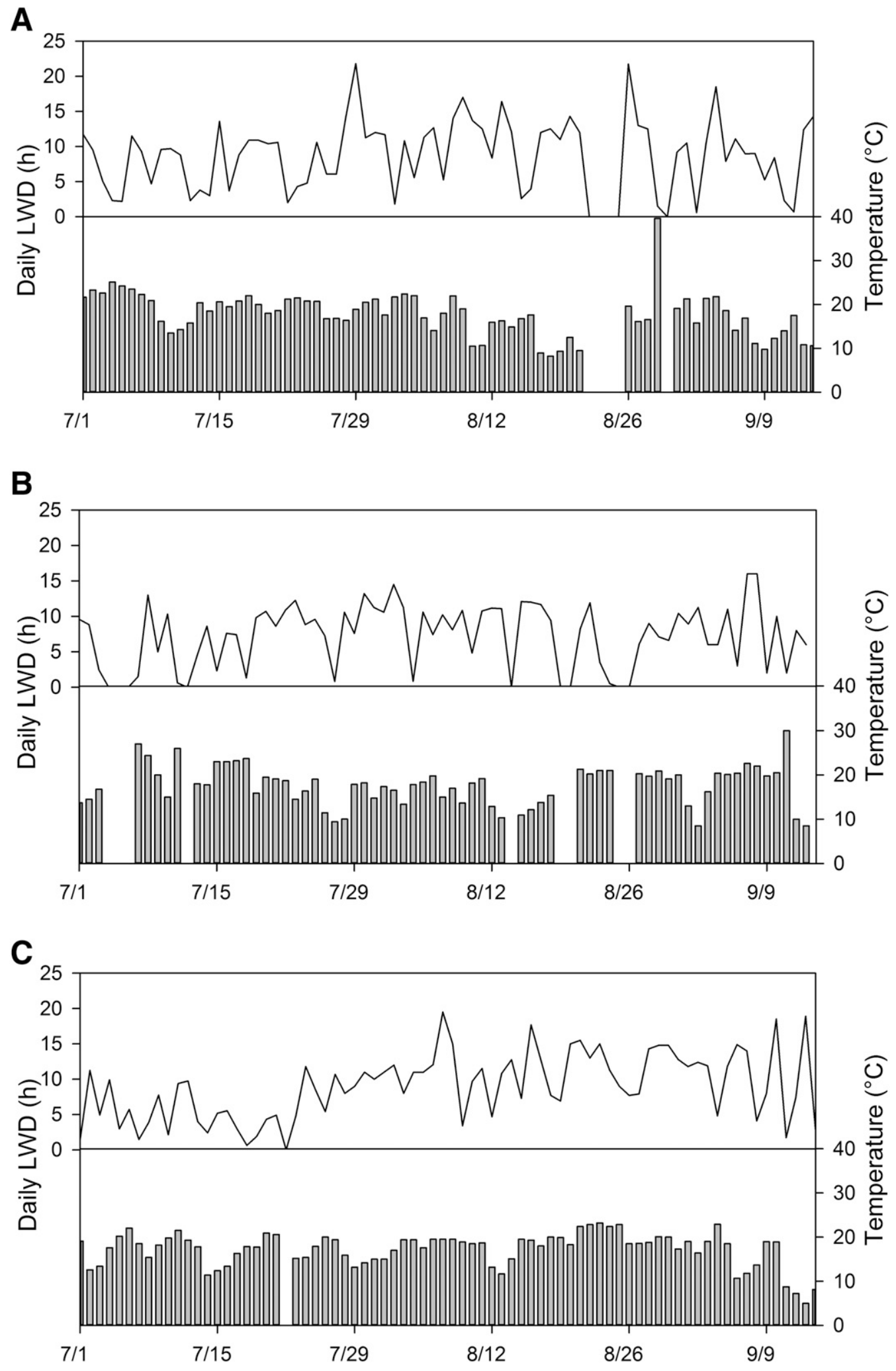

Fig. 1. Daily leaf wetness duration (LWD, solid line) in continuous hours per day, and average daily temperature during the same period (vertical bars) for 2012 (A), 2013 (B), and 2014 (C). Gaps in temperature data reflect days on which no LWD was recorded. 
In this model, the observations $y_{i}$ (i.e., AFR_Cnt) have a probability of $\sigma$ being zero, whereas $\lambda$ is the expected count value for $y_{i}$ in the Poisson distribution (stochastic process type i). This part is a binary logistic model. In the cases where the AFR_Cnt $>0$ (stochastic process type ii), we assumed a Poisson distribution, and therefore a Poisson regression, could be used.

To evaluate the accuracy of the warning system, we modeled the effect of INF on AFR_Cnt or AFR_Inc for each experimental treatment. We used the cumulative daily INF calculation (Acc_INF) for each harvest date to model the effect of INF on AFR. AFR_Cnt and AFR_Inc data were not independent because only mature fruit were harvested, whereas immature symptomatic or symptomless fruit present during each harvest were harvested later. Given the first-order Markov chain property of these data, in which the current status is related to the previous status, we included the previous disease status in the model (Asmussen 2003). To compare treatment differences, we then employed a transition model for the pooled data to fit the time series of AFR_Cnt that was assumed to be in a ZIP distribution with the first-order Markov chain property. In this transition model, one fixed effect was from the previous status of AFR occurrence, noted as AFR_Cnt ${ }_{(t-1)}$. The other fixed effects were Acc_INF and the five treatments. We also had two random effects from different replications nested in years for the Poisson component of this ZIP model. For the zeros, a binary logistic regression model was used which had a logit link function:

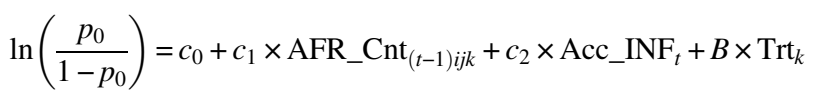

in which $p_{0}$ was the probability of AFR_Cnt $=0$ and AFR_Cnt $(t-1)$, Acc_INF, and Trt were predictors. For the Poisson component where AFR_Cnt $>0$, the final model was as follows:

$$
\begin{aligned}
& \ln \left(\text { AFR_Cnt } t_{i j k}\right)=b_{0}+b_{1} \times \text { AFR_Cnt }(t-1) i j k \\
& +b_{2} \times \text { Acc }_{-} \mathrm{INF}_{t}+B \times \operatorname{Trt}_{k}+\varepsilon
\end{aligned}
$$

in which AFR_Cnt $(t-1)$, Acc_INF, and Trt were the fixed effects and $\varepsilon$ was the component for the nested random effects from replications nested in year. The link function was the natural log. Analyses were performed using the NLMIXED (nonlinear mixed model) procedure in SAS (SAS Institute); pairwise treatment differences were estimated.

\section{Results}

Weather conditions and disease development. Incidence of AFR in nonsprayed control plots ranged from 3.6 to $57.3 \%$ across three years (Table 1). The diseased fruits with sunken brown lesions were scouted 7 to 13 days after the inoculation. In 2012, weather conditions were favorable on the day of inoculation, resulting in rapid AFR development. However, during August prolonged dry periods with maximum daytime temperatures $>35^{\circ} \mathrm{C}$ inhibited AFR development (Fig. 1) (Leandro et al. 2003a; Wilson et al. 1990), so disease incidence for the no-spray control treatment remained $<20 \%$. Exceptionally dry weather during the growing season of 2013 also inhibited AFR development. In contrast, 2014 was exceptionally warm and rainy; 19 moderate-risk warnings and three high-risk warnings occurred during the harvest period.

Fungicide treatments and AFR incidence. In 2012, the AFRStAS issued 18 moderate-risk and four high-risk warnings. Treatments using the warning system saved two fungicide sprays but had equivalent disease control compared with a calendar-based spray schedule, and disease incidence was about $15 \%$ lower than for the nospray treatment (Table 1). Marketable weight did not differ significantly among the treatments with fungicide applications.

During the relatively dry harvest season of 2013, the warning-system treatments saved one fungicide spray compared with the calendar-based treatments, and they did not differ from calendar-based or no-spray control. On average, the warning system resulted in a 1 to $2 \%$ reduction in disease incidence compared with the no-spray control (Table 1).
All fungicide treatments suppressed AFR significantly compared with the nonsprayed treatment in 2014, which reached $100 \%$ symptomatic fruit for some harvests (Fig. 2). The warning system treatments saved one fungicide spray compared with the calendar-based treatments, but the latter had higher marketable fruit weight $(P>$ $0.05)$. During each year, fruit damage caused by other reasons, such as fungal rots, sunburn, animal pecks, or insect injury, did not differ significantly among treatments.

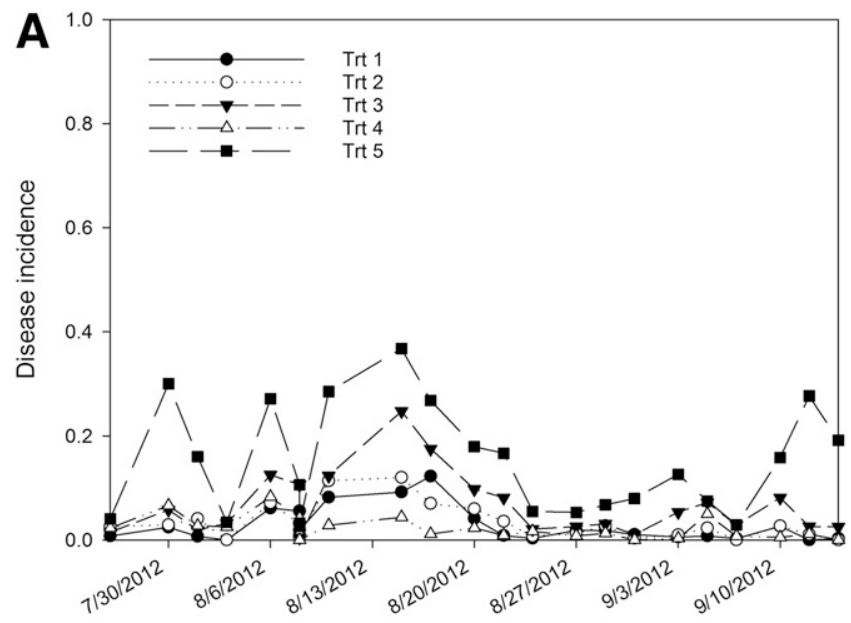

B

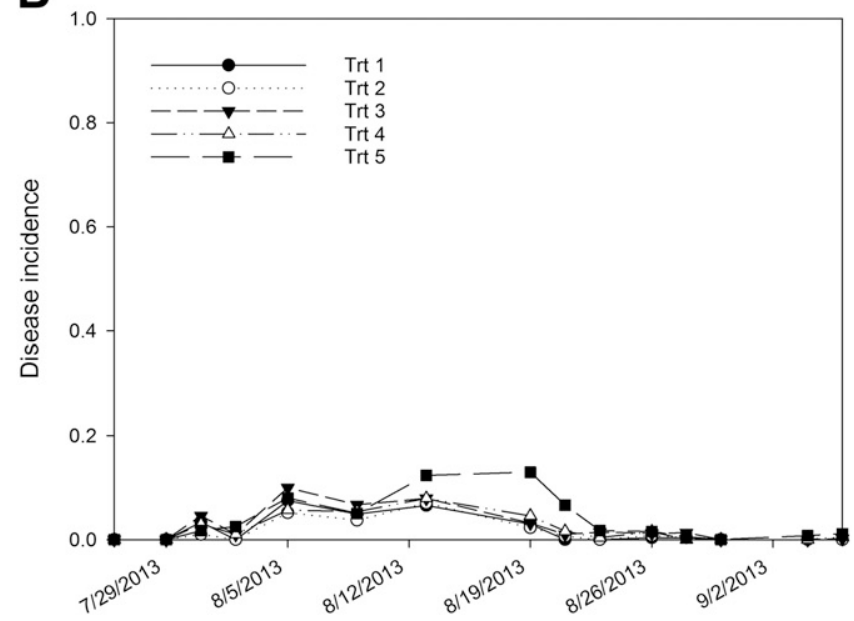

C

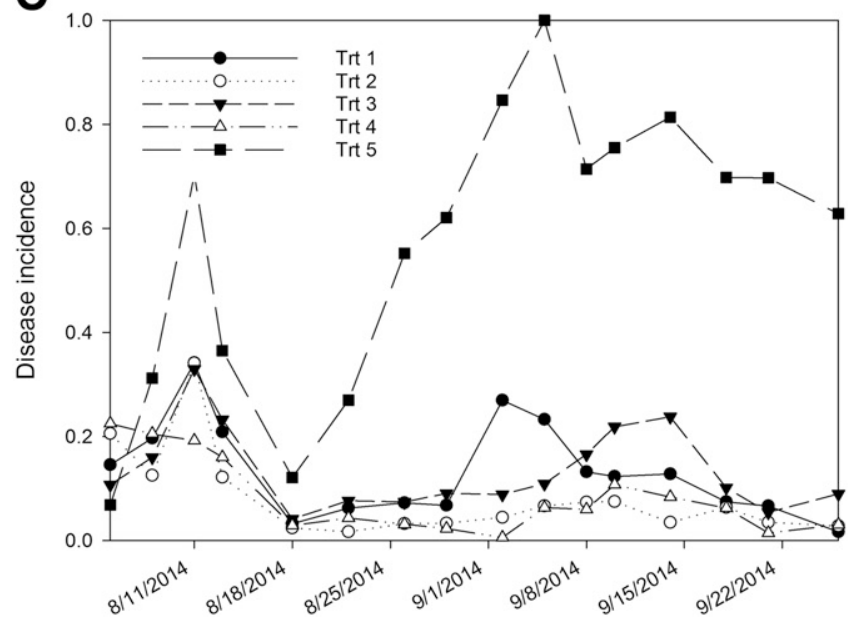

Fig. 2. Disease incidence of anthracnose fruit rot (AFR) for 2012 (A), 2013 (B), and 2014 (C). Each dot represents mean value of AFR incidence of four replications of each treatment (Trt). 
Parameter estimates of ZIP model and treatment effect comparisons for AFR_Cnt. Modeling using Poisson regression indicated that higher counts of fruit with AFR symptoms were associated with higher values of INF and higher numbers of symptomatic fruit in the previous harvest. When modeling with logistic regression for the probability of zero diseased fruit, both INF and AFR_Cnt $(t-1)$ showed a negative effect, and the expected probability of AFR_Cnt $=0$ was 0.307. This means the predicted disease incidence and the AFR fruit number from the preceding harvest negatively influenced the probability of zero AFR fruit in subsequent harvests. The probability of harvesting no fruit with AFR symptoms in a treatment was 0.307 according to this model. The parameter estimates of the ZIP model for the counts of AFR fruit are given in Table 2.

Paired comparisons among the five treatments for differences in AFR_Cnt detected highly significant differences, except for treatment 2 versus treatment 4 , for which means differed by -0.0267 (Table 3). Both treatments used Cabrio and captan, with either the calendar-based or the StAS-based timing. The greatest differences were found between the calendar-based Cabrio and captan treatment (treatment 2) and the no-spray control (treatment 5).

\section{Discussion}

This 3-year study is the first to validate the Florida StAS system outside of the southeast United States. Despite being transported $1,900 \mathrm{~km}$ to different climate, strawberry production system, and type of cultivar, the AFR-StAS system performed effectively across a wide range of weather conditions. Use of the warning system resulted in AFR control and marketable yield that were comparable to those obtained using calendar-based fungicide application programs, with 1.7 fewer fungicide applications per growing season. These findings provide evidence that the AFR-StAS can be a useful management tactic against AFR in Iowa despite the many differences between Iowa and Florida in terms of climate, strawberry production systems, and cultivars. It also adds to the relatively small body of scientific literature assessing issues surrounding portability of disease-warning systems (e.g., Duttweiler et al. 2008; Nita et al. 2006; Shtienberg et al. 2003). These issues are mentioned in review articles about decision support in agriculture but are less commonly analyzed when such a system is moved from its place of origin to new regions or countries (Kim et al. 2010; Magarey and Sutton 2007).

Disease-warning systems should be thoroughly validated in field trials before they are recommended for grower use in regions that differ from those in which the warning system was developed, to account for the impacts of local climate, production system, cultivar, and pathogen ecotypes (Duttweiler et al. 2008; Nita et al. 2006;

Table 2. Parameter estimates of a zero-inflated Poisson (ZIP) regression model for the diseased fruit counts of strawberry anthracnose caused by $\mathrm{Col}$ letotrichum acutatum sensu lato in Iowa in 2012 to 2014

\begin{tabular}{lrcrr}
\hline Parameter $^{\mathbf{y}, \mathbf{z}}$ & Estimate & Standard error & $\boldsymbol{t}$ value & \multicolumn{1}{c}{ Pr } \\
\left.\hline${\text { Intercept }\left(c_{0}\right)}\right)$ & 1.0862 & 0.1308 & 8.31 & $<0.0001$ \\
AFR_Cnt $(t-1)\left(c_{1}\right)$ & -0.3591 & 0.0423 & -8.5 & $<0.0001$ \\
Acc_INF $\left(c_{2}\right)$ & -1.3745 & 0.3430 & -4.01 & $<0.0001$ \\
${\text { Intercept }\left(b_{0}\right)}_{\text {AFR_Cnt }}(t-1)$ & 1.9274 & 0.2357 & 8.18 & $<0.0001$ \\
Acc_INF $\left(b_{2}\right)$ & 0.0204 & 0.0008 & 24.44 & $<0.0001$ \\
Trt 1 & 0.1165 & 0.0599 & 1.94 & 0.0521 \\
Trt 2 & -0.8403 & 0.0603 & -13.95 & $<0.0001$ \\
Trt 3 & -1.1907 & 0.0699 & -17.02 & $<0.0001$ \\
Trt 4 & -0.6514 & 0.0558 & -11.68 & $<0.0001$ \\
Trt 5 & -1.1640 & 0.0672 & -17.32 & $<0.0001$ \\
\hline
\end{tabular}

${ }^{\mathrm{y}} c_{0}, c_{1}$, and $c_{2}$ were parameters for the logistic regression part (equation 3 ) for AFR_Cnt $=0$ in the ZIP model, and $b_{0}, b_{1}$, and $b_{2}$ were the parameters for the Poisson regression part (equation 4) for AFR_Cnt $>0$ in the ZIP model.

${ }^{\mathrm{z}}$ Treatments: Trt $1=$ calendar-based with captan only; $\operatorname{Trt} 2=$ calendar-based with captan and Cabrio; Trt $3=$ Strawberry Advisory System (StAS)-based with captan only; Trt $4=$ StAS-based with captan and Cabrio; and Trt $5=$ nospray control.
Shtienberg et al. 2003). Warning-system validation entails (i) obtaining an acceptable level of disease control over multiple years and sites in the new region, (ii) providing pesticide spray reduction, profitability, and/or more consistent disease control, and (iii) incorporation of the system into commercial growers' overall crop management plans $(\mathrm{Pa}-$ van et al. 2011; Sherman and Gent 2014). The results of our study suggest that the AFR-StAS algorithm may need further refinement for the Midwest. The ZIP model provided insight into potentially significant deviations between StAS model predictions and actual AFR risk under Iowa conditions. Our results also indicated more effective suppression of AFR when using Cabrio compared with captan under high disease pressure, which is consistent with reports from Florida (MacKenzie and Peres 2012).

Our study suggested that the magnitude of fungicide-spray savings from using AFR-StAS in Iowa, and possibly in other parts of the Midwest, is likely to be less than in Florida. But our findings support the assertions of MacKenzie and Peres (2012) on the effectiveness of the system in protecting fruit with fewer fungicide sprays, even for disease-favorable weather conditions during fruit maturation. For example, hot and dry weather conditions during the 2013 growing season in Iowa suppressed AFR epidemic development, in contrast to cooler and wetter conditions that typify the winter growing season in Central Florida. Overall, the binary logistic part of the ZIP model showed that the probability of AFR_Cnt $=0$ was 0.307 , indicating zero AFR fruit count is most likely caused by unfavorable weather.

The StAS performed well in suppressing AFR while reducing fungicide sprays (Table 3). According to the ZIP model, however, previous disease incidence significantly affected current disease incidence. As a result, it may be advisable to reduce the warning system's action threshold if preceding AFR incidence (based on harvested fruit) exceeds a threshold level. However, such a threshold would need to be determined in field trials across multiple sites and years to determine how building a "memory" into the warning system would be economically justifiable. Before the StAS is modified, the grower may choose to convert to the calendar-based spray strategy if they feel poor control is occurring. In situations with natural infections, the inoculum often arrives as quiescent infections on transplants, so the first spray of StAS could be applied when removal of flowers is stopped to reduce the initial inoculum that may come with the transplants. In our research, uniform inoculation was used because it was the most reliable way to ensure development of an epidemic.

Assessment of disease pressure is a potentially valuable risk assessment component that could be incorporated into the StAS system. With the improvement of pathogen detection methods, it is possible to quantify inoculum in field plots using DNA-based assays such as loop-mediated isothermal amplification (LAMP) or quantitative polymerase chain reaction (Debode et al. 2015; Zhang et al. 2016). In our study, AFR symptoms appeared on fruit 7 to 13 days

Table 3. Pairwise comparisons of the five treatments shown in Table 1 on the diseased fruit counts of strawberry anthracnose caused by Colletotrichum acutatum sensu lato in Iowa during field evaluation trials in 2012, 2013, and 2014

\begin{tabular}{lrcrr}
\hline Treatment comparison $^{\mathbf{z}}$ & Estimate & Standard error & $\boldsymbol{t}$ value & \multicolumn{1}{c}{ Pr } \\
\hline Trt 1 versus Trt 2 & 0.3504 & 0.07562 & 4.63 & $<0.0001$ \\
Trt 1 versus Trt 3 & -0.1889 & 0.05766 & -3.28 & 0.0011 \\
Trt 1 versus Trt 4 & 0.3237 & 0.07174 & 4.51 & $<0.0001$ \\
Trt 1 versus Trt 5 & -0.8904 & 0.05283 & -16.85 & $<0.0001$ \\
Trt 2 versus Trt 3 & -0.5393 & 0.07113 & -7.58 & $<0.0001$ \\
Trt 2 versus Trt 4 & -0.0267 & 0.08287 & -0.32 & 0.7477 \\
Trt 2 versus Trt 5 & -1.2408 & 0.06773 & -18.32 & $<0.0001$ \\
Trt 3 versus Trt 4 & 0.5127 & 0.06708 & 7.64 & $<0.0001$ \\
Trt 3 versus Trt 5 & -0.7014 & 0.04501 & -15.58 & $<0.0001$ \\
Trt 4 versus Trt 5 & -1.2141 & 0.06308 & -19.25 & $<0.0001$ \\
\hline
\end{tabular}

${ }^{\mathrm{z}}$ Treatments: Trt $1=$ calendar-based with captan only; Trt $2=$ calendar-based with captan and Cabrio; Trt 3 = Strawberry Advisory System (StAS)-based with captan only; Trt $4=$ StAS-based with captan and Cabrio; and Trt $5=$ nospray control. 
after inculcation, whereas LAMP can detect the pathogen 2 days after inoculation (Zhang et al. 2016). Therefore, further research should be undertaken to investigate the advisability of incorporating inoculum detection into the StAS model regarding sampling strategies, detection timing, and which parts of the plant to sample.

Our results underline the important role played by strobilurin fungicides in integrated pest management-based management of AFR, particularly under periods of high disease risk. However, emergence in Florida of $C$. acutatum strains that are highly resistant to QoI fungicides represents a threat to both calendar-based and StAS management systems, because both utilize strobilurin fungicides (Forcelini et al. 2016). This development emphasizes the need to develop methods to rapidly detect strobilurin-resistant strains of $C$. acutatum to contain their spread, and to modify AFR management systems if these strains continue to proliferate.

\section{Literature Cited}

Asmussen, S. 2003. Applied Probability and Queues. Springer Science \& Business Media, New York, NY.

Cameron, A. C., and Trivedi, P. K. 2013. Regression Analysis of Count Data. Cambridge University Press, New York, NY.

Cordova, L., Madden, L., Amiri, A., Schnabel, G., and Peres, N. A. 2017. Metaanalysis of a web-based disease forecast system for control of anthracnose and botrytis fruit rots of strawberry in southeastern united states. Plant Dis. 101:1910-1917.

Debode, J., Van Hemelrijck, W., Xu, X. M., Maes, M., Creemers, P., and Heungens, K. 2015. Latent entry and spread of Colletotrichum acutatum (species complex) in strawberry fields. Plant Pathol. 64:385-395.

Duttweiler, K. B., Gleason, M. L., Dixon, P. M., Sutton, T. B., McManus, P. S., and Monteiro, J. E. B. A. 2008. Adaptation of an apple sooty blotch and flyspeck warning system for the Upper Midwest United States. Plant Dis. 92: 1215-1222.

Ellis, M., and Madden, L. 1993. Studies and observations on the epidemiology and control of anthracnose fruit rot of strawberry in Ohio. Acta Hortic. 348:449-457.

Forcelini, B. B., Seijo, T. E., Amiri, A., and Peres, N. A. 2016. Resistance in strawberry isolates of Colletotrichum acutatum from Florida to quinoneoutside inhibitor fungicides. Plant Dis. 100:2050-2056.

Howard, C. M., Maas, J. L., Chandler, C. K., and Afbregts, E. E. 1992. Anthracnose of strawberry caused by the Colletotrichum complex in Florida. Plant Dis. 76:976-981.

Kim, K. S., Taylor, S. E., Gleason, M. L., Nutter Jr, F. W., Coop, L. B., Pfender, W. F., Seem, R. C., Sentelhas, P. C., Gillespie, T. J., Dalla Marta, A., and Orlandini, S. 2010. Spatial portability of numerical models of leaf wetness duration based on empirical approaches. Agric. For. Meteorol. 150:871-880.

Lambert, D. 1992. Zero-inflated Poisson regression, with an application to defects in manufacturing. Technometrics 34:1-14

Leandro, L. F., Gleason, M. L., Nutter, F. W., Wegulo, S. N., and Dixon, P. M. 2001. Germination and sporulation of Colletotrichum acutatum on symptomless strawberry leaves. Phytopathology 91:659-664.
Leandro, L. F. S., Gleason, M. L., Nutter, F. W., Wegulo, S. N., and Dixon, P. M. 2003a. Influence of temperature and wetness duration on conidia and appressoria of Colletotrichum acutatum on symptomless strawberry leaves. Phytopathology 93:513-520.

Leandro, L. F. S., Gleason, M. L., Nutter, F. W., Wegulo, S. N., and Dixon, P. M 2003b. Strawberry plant extracts stimulate secondary conidiation by Colletotrichum acutatum on symptomless leaves. Phytopathology 93:12851291.

MacKenzie, S. J., and Peres, N. A. 2012. Use of leaf wetness and temperature to time fungicide applications to control anthracnose fruit rot of strawberry in Florida. Plant Dis. 96:522-528.

Magarey, R. D., and Sutton, T. B. 2007. How to create and deploy infection models for plant pathogens. Pages 3-25 in: General Concepts in Integrated Pest and Disease Management. A. Ciancio and K. G. Mukerji, eds. Springer, Dordrecht, the Netherlands.

Nita, M., Ellis, M. A., Wilson, L. L., and Madden, L. V. 2006. Evaluation of a disease warning system for Phomopsis cane and leaf spot of grape: A field study. Plant Dis. 90:1239-1246.

Pavan, W., Fraisse, C. W., and Peres, N. A. 2011. Development of a web-based disease forecasting system for strawberries. Comput. Electron. Agric. 75: 169-175.

Peres, N. A., Seijo, T. E., and Turechek, W. W. 2010. Pre- and post-inoculation activity of a protectant and a systemic fungicide for control of anthracnose fruit rot of strawberry under different wetness durations. Crop Prot. 29: 1105-1110.

Poling, E. B. 2008. Anthracnose on strawberry: Its etiology, epidemiology, and pathology, together with management strategies for strawberry nurseries, proceedings of the ASHS annual conference, Austin, Texas, 18 July 2004. HortScience 43:58-80.

Rowley, D., Black, B. L., Drost, D., and Feuz, D. 2011. Late-season strawberry production using day-neutral cultivars in high-elevation high tunnels. HortScience 46:1480-1485.

Sherman, J., and Gent, D. H. 2014. Concepts of sustainability, motivations for pest management approaches, and implications for communicating change. Plant Dis. 98:1024-1035.

Shtienberg, D., Shwartz, H., Oppenheim, D., Zilberstaine, M., Herzog, Z., Manulis, S., et al. 2003. Evaluation of local and imported fire blight warning systems in Israel. Phytopathology 93:356-363.

Sjulin, T. M. 2008. Special problems in nursery propagation of day-neutral strawberry cultivars susceptible to Colletotrichum acutatum. HortScience 43: 78-80.

Smith, B. J. 1990. Morphological, cultural, and pathogenic variation among Colletotrichum species isolated from strawberry. Plant Dis. 74:69-76.

Turechek, W. W., Peres, N. A., and Werner, N. A. 2006. Pre- and post-infection activity of pyraclostrobin for control of anthracnose fruit rot of strawberry caused by Colletotrichum acutatum. Plant Dis. 90:862-868.

Wilson, L., Madden, L., and Ellis, M. 1990. Influence of temperature and wetness duration on infection of immature and mature strawberry fruit by Colletotrichum acutatum. Phytopathology 80:111-116.

Zhang, X., Harrington, T. C., Batzer, J. C., Kubota, R., Peres, N. A., and Gleason, M. L. 2016. Detection of Colletotrichum acutatum sensu lato on strawberry by loop-mediated isothermal amplification. Plant Dis. 100:1804-1812. 